\title{
Construction of Smart Campus Based on Situational Awareness in the Era of Big Data
}

\author{
Yang Liu, Liang-Shan Shao \\ Liaoning Technical University \\ Institute of Environmental Science and Engineering, fuxin , China \\ E-mail: 116084911@qq.com
}

\begin{abstract}
Big data as a new data management technology, based on the current Internet of things and cloud computing "smart campus" has an important role in the construction. "Smart campus" as an information construction of educational entities, the value of big data mining has a new significance. The combing of the concept of context aware intelligent campus construction and the situation of using qualitative and quantitative methods, to students as the breakthrough point, combined with student work actual needs, construction of campus smart six platforms and two systems, were analyzed based on the significance of situational awareness of the wisdom of the campus construction in the era of big data.
\end{abstract}

Keyword-age of big data; context awareness; smart campus; first exploration

\section{THE DEFINITION OF CORE CONCEPTS}

\section{A. Big Data Concept}

Big data usually refers to a certain period of time can not be used with conventional software tools to capture the contents of the data collection, management and processing. From this definition we can see that the data has 3 characteristics, namely, industry-recognized 3V properties:size of data volumes, the variety of data types and the velocity of data processing. In addition, there are $4 \mathrm{~V}+1 \mathrm{c} 5$ big data expert, increase the authenticity of the data on the basis of the $3 \mathrm{~V}$ consist of veracity or vitality or value and complexity.

\section{B. The Definition of Smart Campus}

"Smart campus" refers to the Internet as the Foundation, based on application service system and the construction of teaching, research, administration and campus life as one of intelligence and wisdom of teaching, learning and living environment. Mainly through the use of cloud computing, virtualization and networking technologies to change the school teachers and students, staff and school resource way to interact with each other, the school's teaching, research, administration and campus resources and systems integration to improve clarity, flexibility and speed of response to interact, so as to realize the wisdom of campus services and management mode.

\section{The Definition of Situational Awareness}

In 1994 Theimer and Schilit first proposed the concept of situational awareness, which refers to the use of software applications, the location of nearby people and objects of the collection of adaptive operation of the software. With the gradual deepening of the context aware research, its content also is expanding constantly, Dey et al. The adaptive idea into the context aware services in, but only limited to realize the adaptive software system by using user context information. Salber et al defined the context aware service as the real time context aware, providing maximum flexibility service. Dey and Abowd further expand the application field of context awareness, and define the context aware system as a system that can provide relevant information or service to users by using context information.

Wan Yahong context-aware application refers to the system context information, intelligently determine user behavior and purpose and provide information or services to the user, human change in the way people interact with the situation with and within the community. Zhang Xianggang considered separately from the consumer perspective and functional focus in two ways to define and understand the context-aware.

Guanling Chen and David Kotz divided the situational awareness into the active situation and the passive situation. Anind K.Dey and Gregory D.Abowd obtained a more clear definition of situation awareness: if a system using context information and user task related information or services, then the system is in a context aware system, service provision is context aware service to users.

\section{THE NECESSITY OF BUILDING A SMART CAMPUS IN THE ERA OF BIG DATA}

The era of big data the smart campus of is the technology wisdom, educational wisdom, the wisdom of humanity, intelligence services, management wisdom, the wisdom of life for the campus of the characteristics of development of new mode, is information construction of colleges and universities to the higher level development of embodiment, can provide strong found the problem, problem analysis, problem solving ability, the use of smart campus innovation management has a strong development potential.

According to the <Ministry of education the education informatization ten years development planning (2011-2020)> on "strengthening the construction and application of digital campus, the use of advanced network and information technology, integration of resources, to build advanced, efficient and practical higher education information infrastructure” requirement, this paper 
combined with actual situation of colleges and Universities, and carry out the wisdom of campus design and construction, School of information technology to achieve leapfrog development and to enhance the ability of school management and service.

According to Ministry of education $<$ Ten years of educational information development plan (2011-2020) > on "strengthening the construction and application of digital campus, the use of advanced network and information technology, integration of resources, the construction of an advanced, efficient, practical higher education information infrastructure" requirement, this paper the actual situation, to carry out wisdom campus design and construction, the school information technology to achieve leapfrog development, so as to improve the ability of school management and service.

\section{THE PRESENT SITUATION AND MAIN PROBLEMS OF SMART CAMPUS CONSTRUCTION}

Smart campus of construction to the service for teachers, students, teaching and research work as the direction, in order to optimize the teaching application, improve the service to the teachers and students as the core, to integrate resources, information sharing as the main line, to create a standard, efficient, unified, intelligent platform management service and information service platform as the focus, on the basis of the construction and development of the pre university digital, networking and cloud computing platform based on, comprehensive to further improve the campus information application and service level.

Nanjing University of Posts and Telecommunications summarized a smart campus design based on Internet of things. The overall application framework of planning smart campus includes four aspects, the unified portal service, service integration, data fusion and network convergence, information standard system and security maintenance system as the support system of the whole framework.

Zhejiang University, the planning of intelligent campus understanding for high-speed Internet, a thorough perception, more scientific decision-making, more real-time control, more convenient services, service-oriented computing, such as the six aspects. On this basis, the framework of the smart campus, including the network infrastructure, public support platform, smart campus integrated information services, standard specifications and institutional mechanisms, such as intelligent application system construction.

In foreign countries, many colleges and universities research institutions have conducted a detailed study of the wisdom of the campus. Such as Indore, India's science and Technology Research Institute (IIST2) established a huge intelligent campus, to promote the use of education resource planning (ERP) software, in order to maximize play the potential of the campus, optimize the allocation of resources.

In the University of Southern Calif, is also gradually realize the smart campus. Through the use of a computer, the control of the campus energy system can get a graphical campus monitoring results. Construction enterprise buildings integrator (EBI) in the campus of the University of Southern California to track and control heating, ventilation and air conditioning (HVAC), and achieved good results.

At the same time, there are still many problems in the construction of the wisdom campus at the same time:

\section{A. Islands of Information are Widespread}

- The data of the new students can not be synchronized to various departments in a timely manner, it is difficult to effectively carry out the work of various departments.

- Lack of information exchange between student status changes and personnel changes resulting in financial revenue and expenditure loophole.

- Student information service and the logistics sector is not unified, student emergency difficult to handle.

B. Pay Attention to the Management and Neglect of Service

When the student's report: for the registration process can not be timely access, welcome to the scene of disorder.

Students in the school time: all kinds of applications need to fill in a large number of duplicate information,very complicated.

When students leave school: unclear formalities approval, still need to each business department seal line.

\section{Teaching And Learning Less Interaction}

Teaching and learning interaction is a single, students have a problem not to know how to facilitate the feedback to the teacher, to seek solutions.

Teaching resources do not have an effective sharing mechanism, students can only find a teacher to manually copy the electronic courseware.

The lack of students' autonomous learning environment, students complete the course study, job submission, the issue of the exchange of information technology.

Teachers for students to practice the situation, there is no effective means to track assessment.

\section{SMART CAMPUS CONSTRUCTION FRAMEWORK}

The construction of smart campus aims to improve the quality of campus students' learning and living environment, and to build a comprehensive information service platform, which is intelligent, innovative and open. Intelligent campus is the basis of intelligent network infrastructure, followed by the application of intelligent systems and platforms.

\section{A. Construct Fundamental Platform}

- Information standard construction

Information standard construction [4]is one of the most important intelligence campus construction. Given that the circumstances of each school are different, it is necessary to ensure that the information used by the state and the 
ministry of education and information standards is compatible.

Information standards guarantee that information in the process of collection, processing, exchange, transfer, can have a unified, scientific, standardized classification and description, which can make the information more orderly circulation, and play the comprehensive benefits of information resources.

- Unified identity authentication platform

Construct electronic identity authentication system and realize uniform user management and access control.

Identity authentication system will be an important part of intelligence campus, providing central identity authentication service for each application system and improving the security of intelligence campus of application system. By specifying the corresponding concentration of certification technical specification and providing unified user management interfaces of the application system, finally it realizes the unification of all new user authentication systems centralized management and does the real meaning of central authentication. The system provides all users of intelligence campus with unified identity certification and authority payment. Through the unified information portal, users realize single sign-on to avoid duplication of investment as a whole.

- Unified information portal platform

Constructing the face-to-face information service website (unified information portal platform) releases various information of schools timely. It can provide different information services for the social public , teachers and students and have access to the corresponding entry of campus information management system.

Uniform information portal platform should be the organic integration of information and application of intelligence campus resources into a unified WEB page. As long as users have an account, you can have access to all resources within the scopes of authority. At the same time, the portal to provide personal information service platform, the content and forms of information can be customized. Different users can be fond of according to oneself to customize information and service content and personally set up their own style interface. Users can enjoy the the personal information service which the intelligence campus provides.

- Unified information portal platform

Constructing the face-to-face information service website (unified information portal platform) releases various information of schools timely. It can provide different information services for the social public , teachers and students and have access to the corresponding entry of campus information management system.

Uniform information portal platform should be the organic integration of information and application of intelligence campus resources into a unified WEB page. As long as users have an account, you can have access to all resources within the scopes of authority. At the same time, the portal to provide personal information service platform, the content and forms of information can be customized. Different users can be fond of according to oneself to customize information and service content and personally set up their own style interface. Users can enjoy the personal information service which the intelligence campus provides.

- Air intelligence campus platform

Air platform wisdom campus[5] ,based on integration and information services in all kinds of campus information system by transmission ways,such as operators wireless communication network and 3G network,provides wireless intelligent services for school students. Users not be bound by space and time, and at any time can use mobile phones and other mobile terminal access to require information (subscription), master campus information, the treatment course and send instant messages and real-time interaction and so on.

- Electronic payment platform

Electronic payment platform of intelligence campus contruction is an instant payment system with the bank payment interface. Students who pay cost can use electronic payments for online payment ,such as credit card, electronic cash, electronic checks and electronic wallet, which is the electronic payment online way to save the transaction cost and improve the yield of payment. By docking with the bank payment interface, tuition and fees, examination fees, make-up exam repairing fees, utilities, such as IC card prepaid by phone online payment. This payment system is convenient, quick, safe and efficient.

- Sharing data center platform

Sharing data center platform is a kind of uniform data resources, which is a unified management platform for various structured datas in digital campus, including exchange dates platform which is the important basis of realizing the data sharing of digital campus and offering deep data exploring and data analysis.

\section{B. Construction Application System}

- Meet freshmen management system

New management system according to the actual school recruitment freshmen of process development system, using the system after the register process, which is not more than 10 seconds, and it has a high accuracy data. Standard school orientation process, based on network technology and data sharing ideas, in order to make it more standard, provide efficient collaboration platform for different school departments which are supplemented by campus online payment platform and import the dormitory information to realize the online forecast, primary dormitory and simplify the orientation process and improve the efficiency of orientation in an all-round way.

- Dormitory management system

Student dormitory management system for each intelligence campus is an essential part of the constructions . Some schools are still in the initial stage of

dormitory where management personnel record data, due to the advent of the era of information explosion, this way of manual recording data is lowly efficient. In this case, it urgently needs to introduce computer management and improve the work efficiency and reduce the human input. 


\section{CONCLUSION}

With the advent of the era of information explosion, this kind of intelligence campus building based on its emotion for students graduating from enrolling to study in school life to leave school at various stages to meet the demand of personal information service of student.

Intelligence campus construction is involved in the social aspects of long-term system engineering with the thought of the campus construction should be integrated into more wisdom. Making it accessible to put more advanced technology and management philosophy into the construction of the campus, students will be close to the point of view and solve problems in order that the intelligence campus will better serve students and make the students' study, life and the cultivation of their talents play more important roles.References

[1] Yahong Wan: "system framework based on active reasoning of situations awareness", "computer engineering"12,2004.55-57 page.

[2] Ping Zong: "the research of the design method of wisdom campus", "journal of nanjing university of posts and telecommucications (natural science edition)", 2010, 04.78-81 page.

[3] Tong Zhou:"present situsation and thinking of the intelligence campus contruction", "information and computer ( theory) " 2011,11,23-25 page.

[4] Xichen Shen: "the university information construction standards", "journal of tsinghua university: natural science edition"2003, 04, 47-51 page.

[5] Cuiping Ji: "the intelligence campus information operation support platform of the construction", "modern education technology"2012,02,33-35 page.
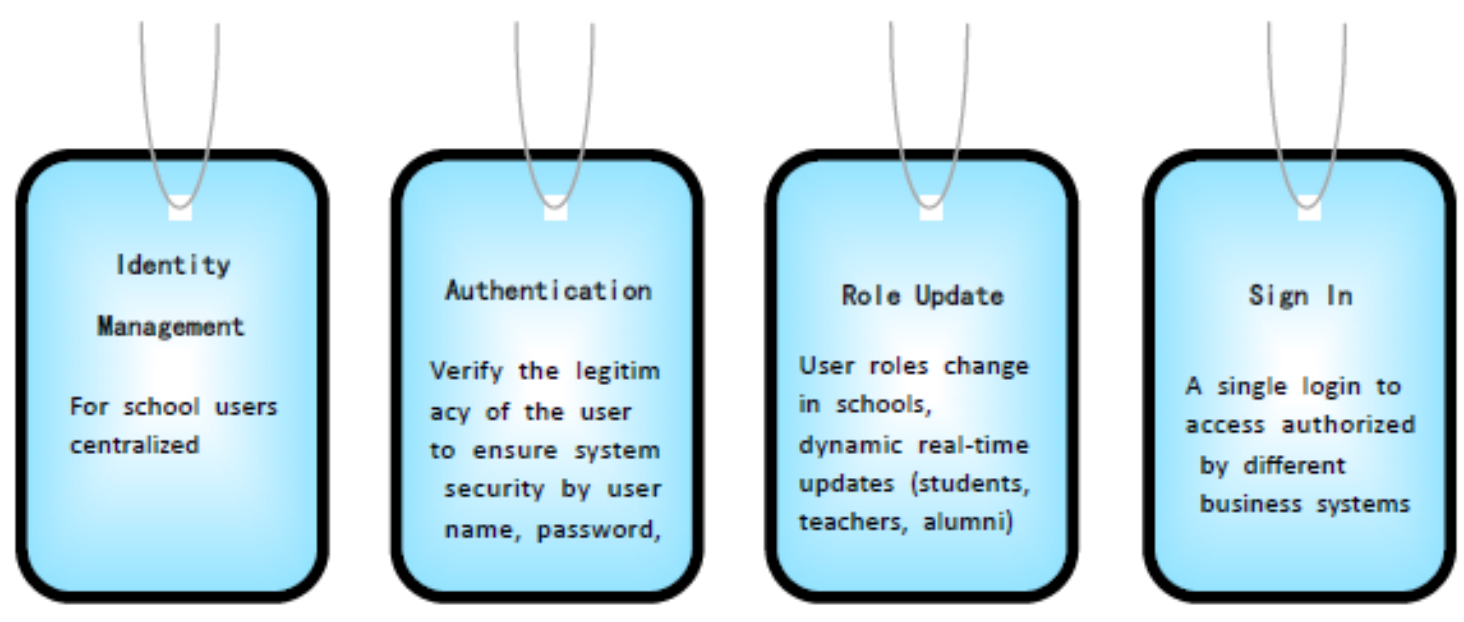

Figure1. Unified identity authentication platform.

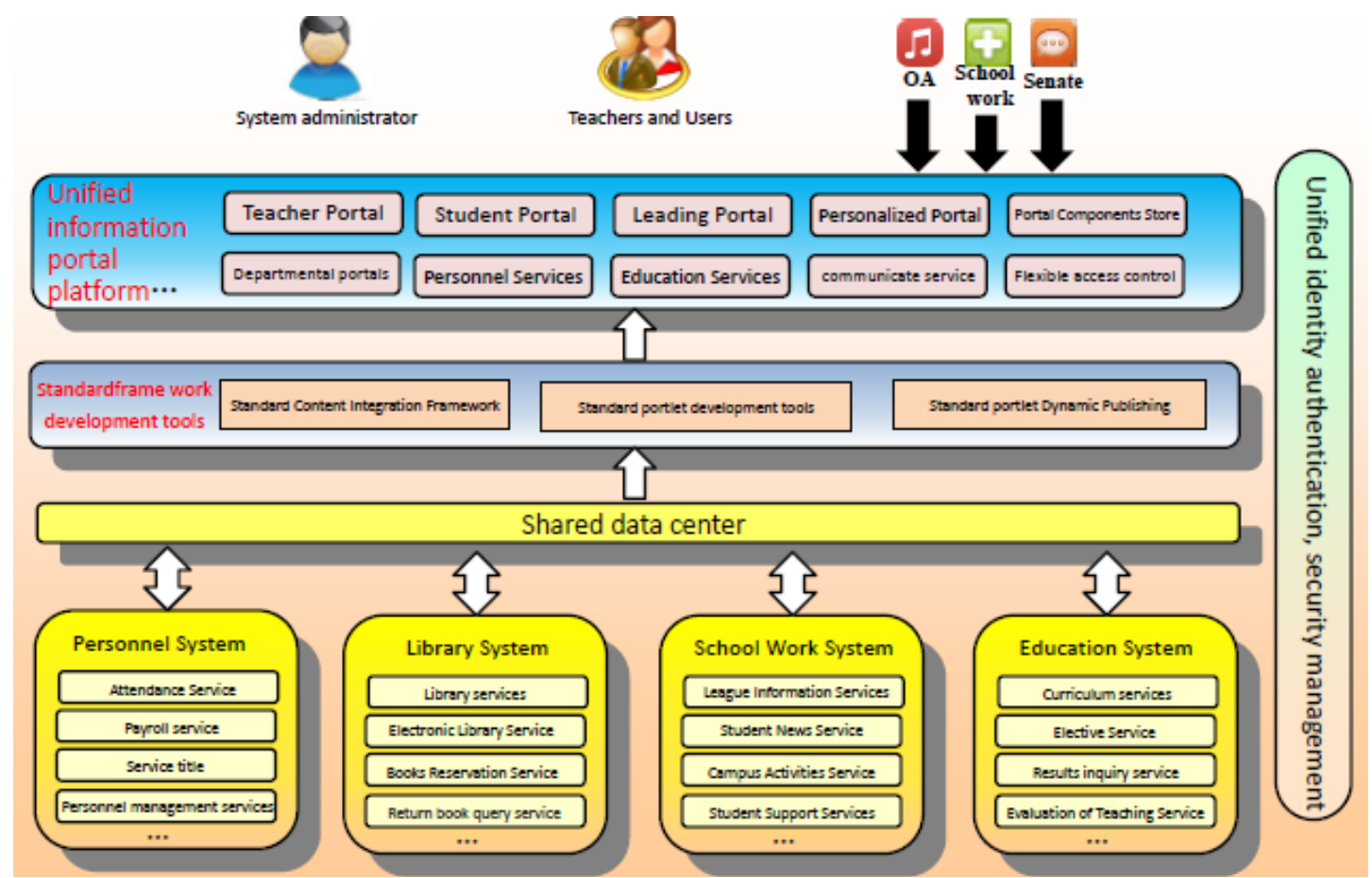

Figure 2. Unified information portal platform. 


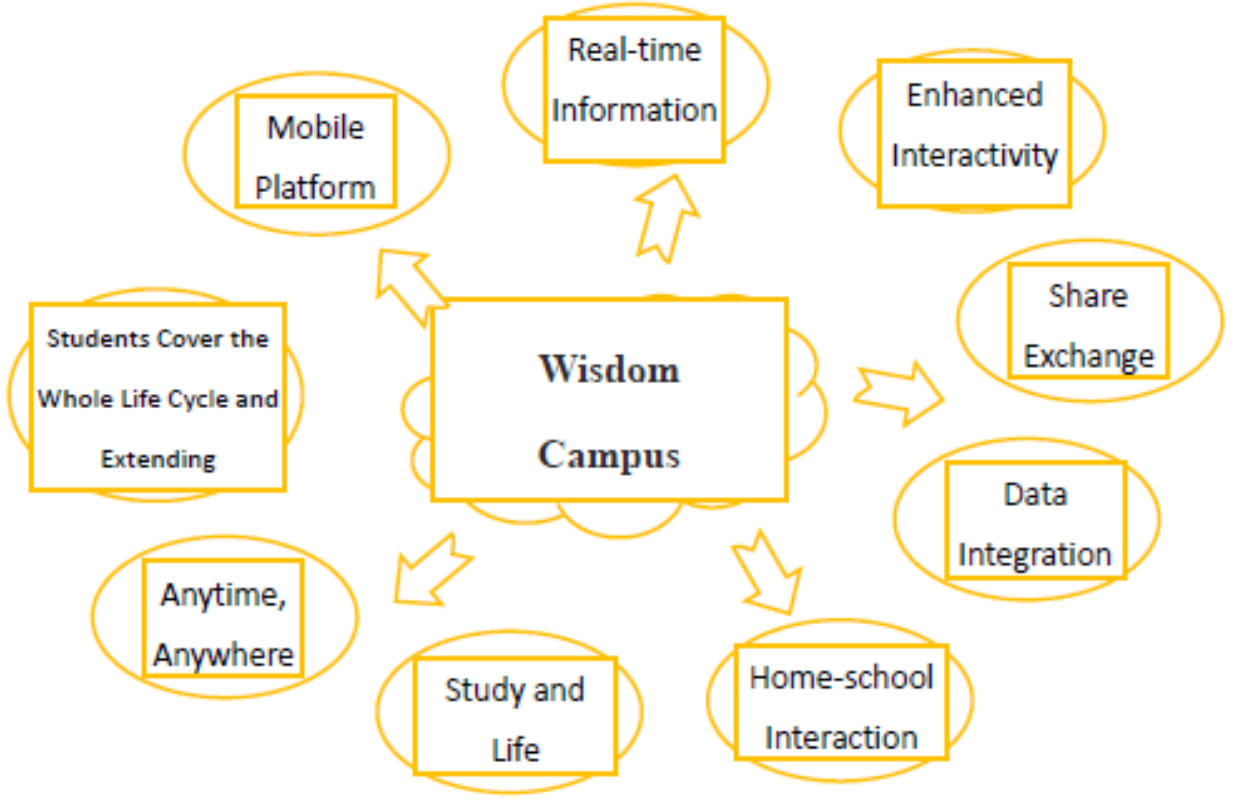

Figure 3. Air intelligence campus platform.

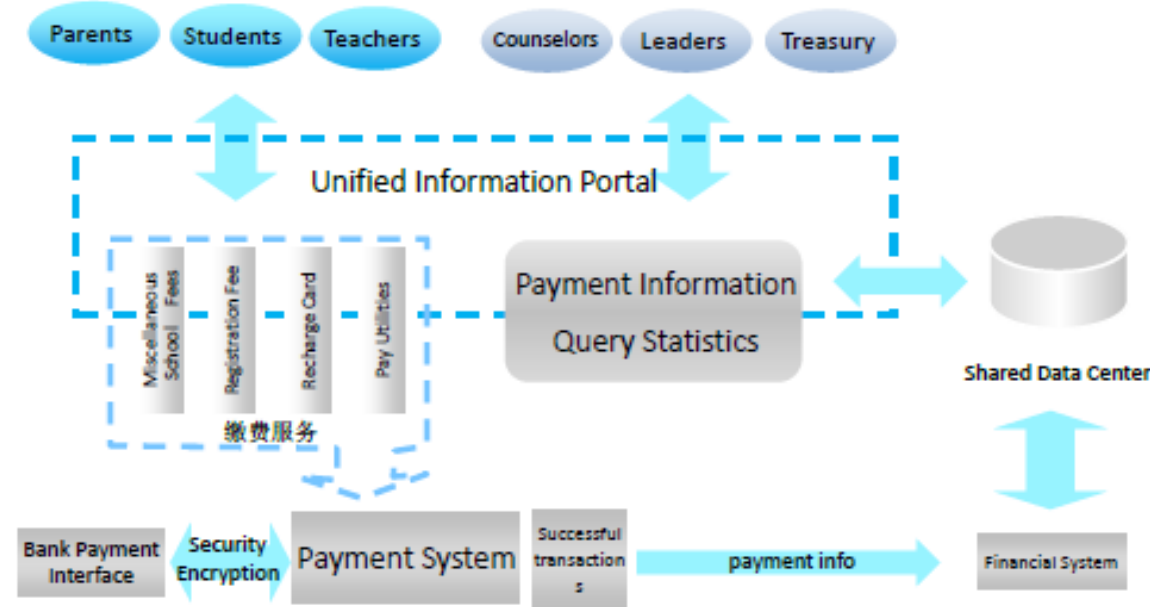

Figure 4. Electronic payment platform. 


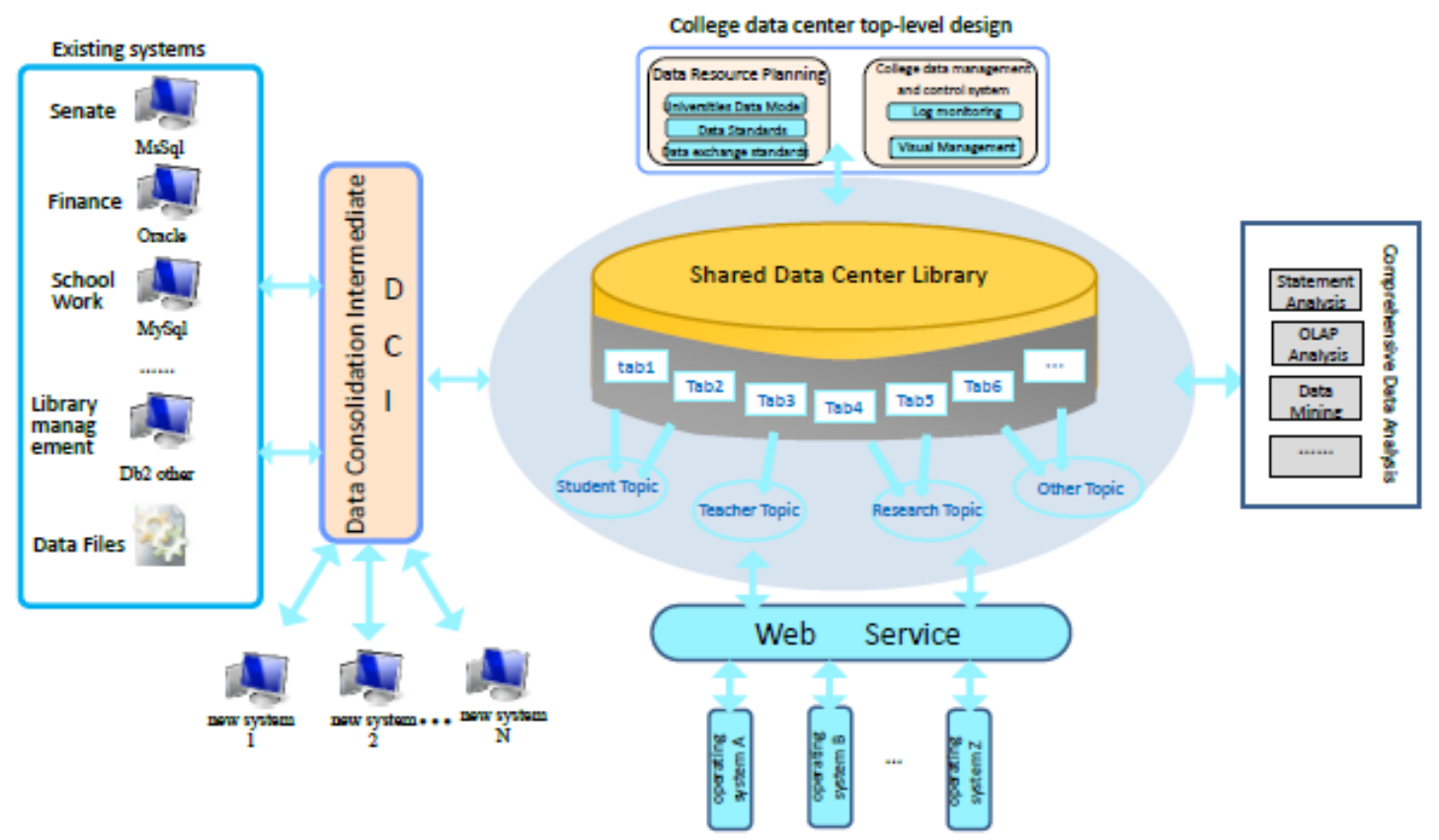

Figure 5. Sharing data center platform.

\section{Online Orientation Process}

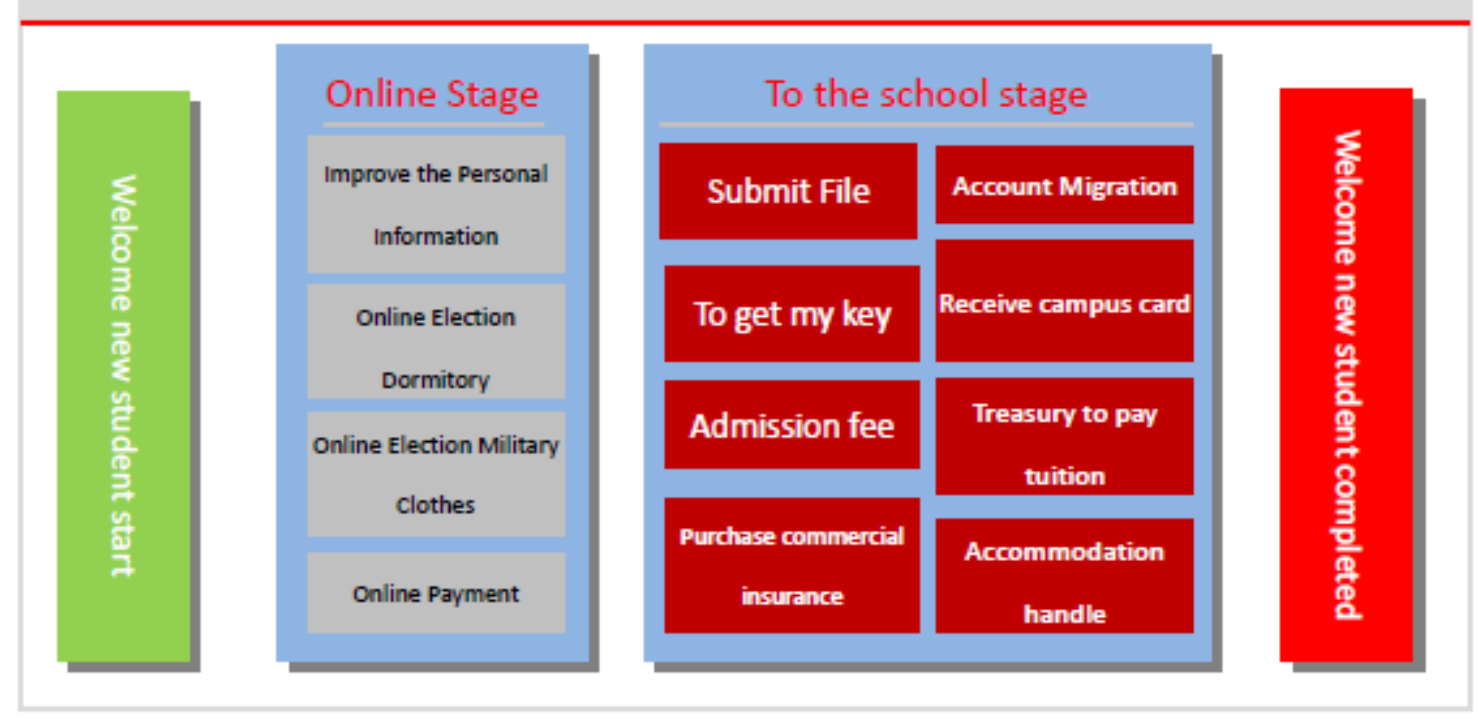

Figure 6. Construction application system. 